\title{
El crédito mercantil. Salta a fines del siglo XVIII
}

\author{
Sara Mata de López \\ CONICET-CIUNSA. CEPIHA. \\ Salta. Argentina
}

\begin{abstract}
El estudio del crédito mercantil a partir de los cartas protocolarizadas existentes en el Archivo Notarial de Salta intenta abordar detenidamente las características que el mismo ofrece, tales como garantías exigidas, plazos e intereses estipulados y rubros comerciales en los cuales el crédito se encuentra más generalizado. Asimismo posibilitará conocer mejor la dinámica mercantil que afecta a la región en el espacio mercantil andino y la vinculación de sus comerciantes con los grandes almacenes de Buenos Aires. Nos permitirá comprender las alternativas del comercio mular y de efectos de Castilla, ambos importantes en la región, del cual participan los comerciantes de mayor giro de la ciudad de Salta. Comprobaremos que los hacendados y comerciantes de Salta participarán del comercio mular en calidad de apoderados o fiadores de los comerciantes altoperuanos y peruanos y de los ganaderos cordobeses de una manera cada vez más excluyente en tanto los comerciantes peninsulares radicados en Salta y dedicados a la comercialización de efectos de Castilla y a la habilitación de tropas de mulas operaron por su cuenta, costo y riesgo abandonando su papel de intermediarios o representantes de las casas comerciales porteñas.
\end{abstract}

\section{El crédito en la sociedad colonial}

El desarrollo mercantil del siglo XVIII, basado en la expansión del textil, no significó sin embargo un cambio sustantivo importante en relación con las formas de operar del comercio a larga distancia, desarrollado por los centros manufactureros y mercantiles de los siglos XIV y XV. Las letras de cambio, los redescuentos y las cadenas crediticias, fueron utilizadas para desarrollar un intercambio cada vez más intenso, del cual participaba un creciente volumen de mercaderías carentes de compradores con una suficiente masa monetaria circulante. La explotación de las minas de plata americana, iniciada en el siglo XVI, arrojó sobre Europa una importantísima cantidad de este metal, lo cual significó, sin duda, un aporte trascendente al desarrollo manufacturero europeo.

El crédito, al suplir la escasez monetaria, está estrechamente relacionado con la circulación mercantil en las economías regionales de la América Española y de los mercados proveedores de efectos de Castilla y esclavos. Aún cuando en ocasiones las casas de Cádiz habilitaron comerciantes que no siempre concretaron con éxito sus negocios, los retornos en 
metálico y moneda fuerte hacia Europa fueron imprescindibles para lograr el abastecimiento regular de almacenes y tiendas coloniales. El capital mercantil europeo volcado en los circuitos americanos activó la circulación de productos regionales, en los cuales el crédito tuvo un papel importante en la medida que reemplazó al circulante en las cadenas de intercambio cuya finalidad era obtener los retornos metálicos hacia la metrópoli.

A pesar de la imposibilidad de determinar con certeza la cantidad de metal amonedado o en piña circulante en las economías regionales, sabemos que gran parte del mismo era remitido a Europa o destinado al sostenimiento de una creciente burocracia. Sin embargo, en los circuitos mercantiles americanos se hallaban a fines del siglo XVIII, cantidades superiores de metales a las existentes en los siglos anteriores, imposibles de cuantificar pero comprobables a través de la documentación de la época. De todas maneras el incremento de la mercantilización, verificable por medio de los volúmenes de mercancías que pueden apreciarse a través de las alcabalas y las guías de comercio de las Aduanas, fue sin duda superior a la disponibilidad de efectivo.

La crónica escasez monetaria no fue superada en el siglo XVIII a pesar del aumento sostenido de la producción de plata. Las necesidades del comercio oceánico, tanto el legal con España como el ilegal con ingleses y franceses, concentraba en los grandes comerciantes los únicas reservas monetarias. El resto del comercio colonial se realizaba por medio de letras de cambio y de operaciones crediticias. ${ }^{1}$

Pero el crédito no solo involucraba mercancías sino también préstamos en efectivo que los comerciantes solían realizar, ya fuera por una disponibilidad transitoria de dinero sin perspectivas ciertas de inversión comercial o por las normas de solidaridad y clientelismo que entre ellos se establecían y que les permitía estructurar redes mercantiles sumamente efectivas para la distribución y comercialización de mercancías en vastos territorios regionales.

Otras fuentes de financiación de las operaciones comerciales fueron los préstamos obtenidos de las cofradías, las capellanías o el acceso a donaciones y capitales administrados por las órdenes religiosas para el sostenimiento de hospitales y hospicios. Si bien el crédito eclesiástico fue muy bien estudiado en relación con la propiedad agraria, los prestamos realiza-

1 Brading, D.A.: Mineros y comerciantes en el México Borbónico 1763-1810. México, 1983, págs. 142-143. 
dos a los comerciantes por las organizaciones religiosas y laicas a ellas vinculadas han sido poco analizados por la historiografía colonial. ${ }^{2}$ También los comerciantes obtenían dinero en préstamo de las viudas que de esa manera, en algunos casos, accedían a una renta destinada a su subsistencia, o de los bienes de menores, ya que en estos casos el alcalde disponía, con autorización del defensor de menores, entregarlos hasta la mayoría de edad de los huérfanos a persona de "abono", quien los garantizaba con propiedades rurales o urbanas. Aún cuando no siempre estos bienes eran reducidos a dinero efectivo, hemos encontrado suficientes ejemplos que nos permiten afirmar que eran una posibilidad bastante frecuente. A finales del siglo XVIII, la expulsión de los jesuitas, y el posterior remate de sus bienes, posibilitó a las Juntas de Temporalidades el otorgamiento de préstamos. En todos estos casos los créditos estaban garantizados con propiedades y el rédito pactado y legal era del $5 \%$ anual.

Nuestro interés, en esta oportunidad, se centrará tan sólo en las características del crédito mercantil - tanto en mercancías como en efectivoestudiando los rubros comerciales involucrados, la participación como intermediarios y como acreedores de los comerciantes instalados en la ciudad de Salta y las variaciones operadas entre 1750 y 1800 en los montos del crédito comercial.

\section{Comercio regional. El crédito mercantil en Salta}

Por su ubicación en el fértil valle de Lerma, al sur del espacio andino meridional, Salta fue desde el momento de su fundación una plaza importante en los circuitos mercantiles que vinculaban al Río de la Plata y el Tucumán con los centros comerciales y mineros andinos, particularmente Cuzco y Potosí. Aun cuando Salta fue tránsito obligado del aguardiente y el vino cuyano, del ganado en pie y el sebo y jabón de la jurisdicción del Tucumán, de los tejidos cordobeses y hasta de la yerba mate paraguaya, el rubro comercial más importante era el ganado mular, que criado en las estancias de Córdoba, Buenos Aires y Santa Fe, llegaba a Salta a engordar en los potreros del valle de Lerma antes de emprender el largo viaje hacia el Perú o las "provincias de arriba", destino de la mayor parte de las tropas que partían de las tabladas de Salta entre los meses de enero y abril de cada

2 Ibídem, págs. 137-139. Kicza, John E.: Empresarios coloniales. Familias y negocios en la ciudad de México durante los Borbones. México, 1986, págs.71-77. 
año. Si bien el comercio mular comenzó a desarrollarse desde las primeras décadas del siglo XVII, se incrementó notablemente en el XVIII. A través de los registros de sisa, Nicolás Sánchez Albornoz demuestra la notable expansión de este comercio en la década de 1770, seguida por la retracción que producen las rebeliones altoperuanas de 1780 y finalmente la existencia de una nueva fase expansiva a partir de 1796, que se prolonga en los primeros años del siglo XIX. ${ }^{3}$

Junto con el comercio mular, transitaban y se comercializaban en Salta efectos de Castilla y esclavos ingresados por el puerto de Buenos Aires. Sin embargo, su papel como distribuidor hacia los centros altoperuanos no es relevante. En general, los efectos de Castilla que tienen como destino las minas altoperuanas provienen directamente del puerto de Buenos Aires. Las mercancías europeas vendidas en Salta abastecen el mercado local y sus excedentes son remitidos a otras ciudades del Tucumán, especialmente Belén y Santa María, en el valle calchaquí, llegando incluso hasta las ciudades de Catamarca y La Rioja. Sólo cuando la oferta superaba la demanda, parte de estas mercancías eran llevadas para su reventa a los centros mineros. Los internadores y fletadores de tropas de mulas tomaban generalmente a crédito en las tiendas efectos de Castilla, junto con los llamados efectos de la tierra, y de allí los retiraban los arrieros, antes de partir, hasta cubrir un 50\% del salario estipulado. De esta manera, sostiene Concolorcorvo que "los comerciantes o tenderos de Salta se hacen cargo de habilitar en plata y efectos a la gente de la tropa ... y este comercio se cuenta por el más efectivo y útil a los mercaderes de Salta". ${ }^{4}$

La comercialización de los efectos de Castilla, al igual que las mulas, sufrió las alternativas coyunturales derivadas de situaciones internas, entre ellas la rebelión altoperuana, y externas, particularmente las guerras de España contra Inglaterra y Francia. Los efectos de la tierra, en cambio, demostraron poseer autonomía relativa en relación a los centros mineros altoperuanos y al puerto de Buenos Aires. Decimos relativa por cuanto en algunas circunstancias, como la introducción de aguardientes y vinos catalanes por el puerto de Buenos Aires en la década de 1780, provocó la reorientación del comercio cuyano que perdió el mercado porteño y saturó con una remisión cada vez mayor los mercados de Salta, Tucumán y Jujuy. De

3 El promedio anual de mulas comercializadas en Salta fue el siguiente: 1751-1765, 24.000; 1766-1779, 33.000; 1780-1794, 18.000, y 1795-1808, 31.000. Sánchez Albornoz, Nicolás: "La saca de mulas de Salta al Perú. 1778-1808". Anuario IIHR, n. . 8, Rosario, 1968, pág. 275.

4 Concolorcorvo: El lazarillo de ciegos caminantes. Madrid, 1959, pág. 318. 
todas maneras el comportamiento del mercado regional muestra un mayor grado de estabilidad. 5

Al igual que en el resto de Hispanoamérica el comercio regional se realizaba básicamente a crédito. Las deudas protocolarizadas frente a escribanos, si bien representan sólo aquella parte de la actividad mercantil que, por una u otra razón, escapaba a la práctica corriente de consignaciones y poderes que sustraía de las escribanías coloniales la mayor parte de las operaciones mercantiles, constituyen un dato importante como indicador de las características del comercio, de los flujos mercantiles, de las relaciones interregionales y de los ciclos económicos de un espacio que, sin duda, superaba a la ciudad de Salta.

Los montos del crédito mercantil, obtenidos a través de los protocolos notariales correspondientes a los seis primeros años de cada década, ${ }^{6}$ muestran con claridad las alternativas y avatares sufridos por el comercio regional entre 1770 y 1805 . A pesar de no contar con un análisis de los precios de las mercancías más representativas, indicador importante en el análisis económico de las sociedades, es interesante señalar la depresión económica evidenciada en el período 1790-1795. El crédito mercantil registrado para ese quinquenio representa tan sólo el 13,3\% del total del crédito otorgado para todo el período. Esto, en parte, puede ser atribuido a la contracción del comercio mular iniciada en la década de los años 80 y prolongada hasta fines del siglo XIX.

El crédito mercantil se incrementó notoriamente en Salta en el período 1800-1805, particularmente en el comercio mular. En estos años no sólo aumentó el número de mulas comercializadas hacia el Perú, sino que también el precio de las mismas se duplicó en relación a 1770-1775. El porcentaje de mulas internadas al Perú que estimamos fueron vendidas a crédito en esos cinco años fue del $33.3 \%$ y, si bien el porcentaje de mulas comercializadas a crédito entre 1800-1805 es del 38.6\%, es decir ligera-

5 Mata de López, Sara: "Articulación regional y mercado interno. Salta entre 1780 y 1786 ", en El noroeste argentino como región histórica. Integración y desintegración regional. Estudio del país interior, n. ${ }^{\circ} 3$, Sevilla, 1992, págs. 65-66.

6 Los años seleccionados en esta primera etapa de nuestro trabajo corresponden a los primeros seis de cada década a partir de 1770 . Consideramos que dada la importancia del comercio mular en Salta y su jurisdicción y analizados los datos que sobre el mismo y sus ciclos nos brinda Nicolás Sánchez Albornoz, los años trabajados son altamente representativos, al igual que en relación con el comercio atlántico, ya que abarca —en la década de los años 70 - el período previo a la creación del Virreinato del Río de la Plata y la Reglamentación de Libre Comercio y en la década siguiente los avatares de la introducción de mercancías de ultramar por Buenos Aires como consecuencia de la guerra de España con Inglaterra, sumado a las rebeliones altoperuanas. 


\section{Gráfico I}

Crédito Mercantil. Salta 1770-1805

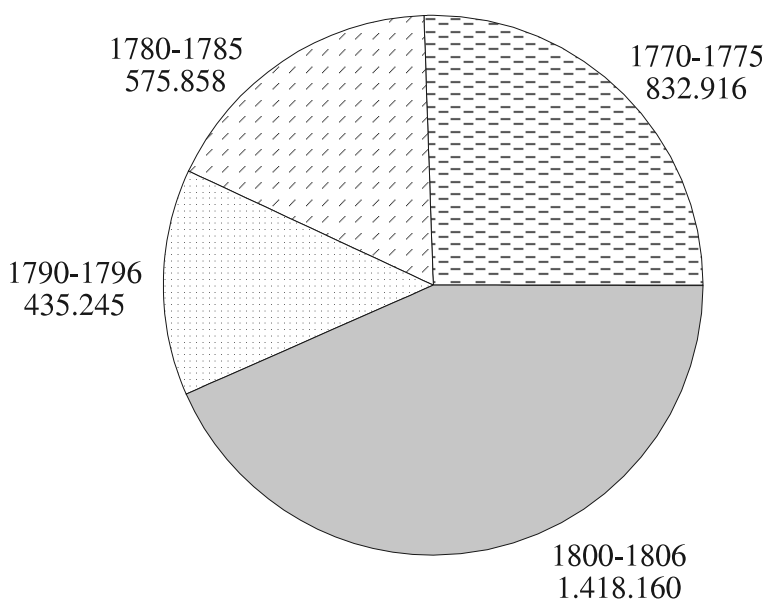

Fuente: ABHS, Protocolos Notariales, 1770-1805

\section{Gráfico II}

\section{Crédito Mercantil}

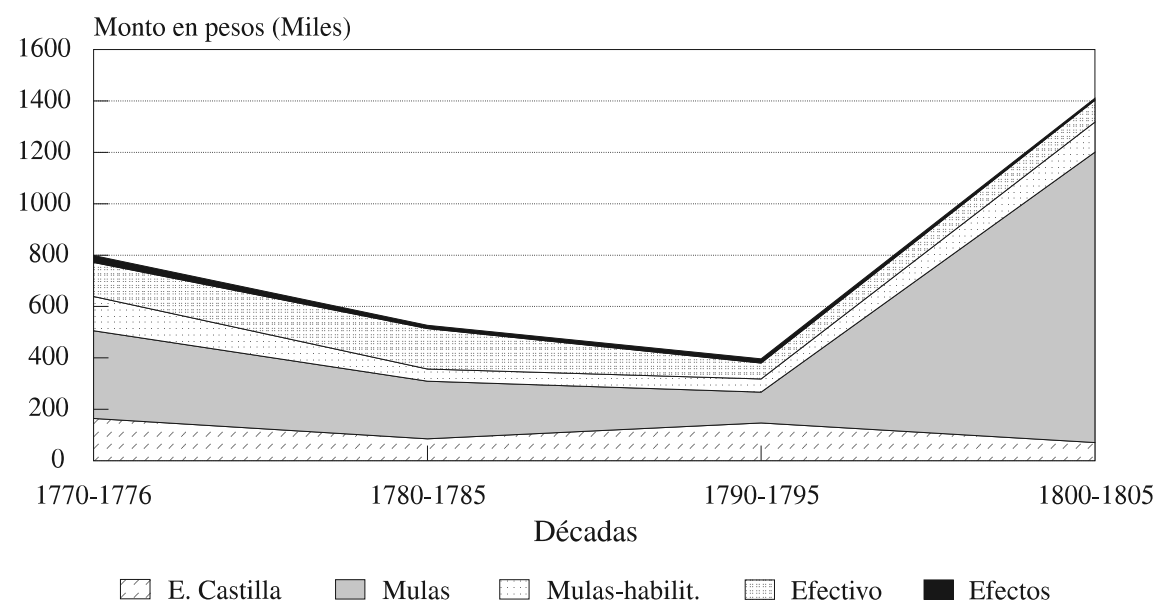

Fuente: ABHS, Protocolos Notariales, 1770-1805 
mente superior a 1770-1775, el mayor precio alcanzado por las mismas incide directamente en el aumento del monto del crédito en este rubro. De ahí el importante incremento del crédito en general y muy particularmente la proporción que del mismo corresponde a las mulas.

Finalmente, entre 1790 y 1795, período de mayor retracción del comercio mular, es interesante observar que las mulas comercializadas a crédito sólo alcanzan un $12.7 \%$ del total. ${ }^{7}$

ESTIMACIÓN DE MULAS COMERCIALIZADAS A CRÉDITO

\begin{tabular}{lccrrrr} 
Periodo & $\begin{array}{c}\text { Crédito en } \\
\text { mulas }\end{array}$ & $\begin{array}{c}\text { Precio por } \\
\text { mula }\end{array}$ & $\begin{array}{c}\text { Total } \\
\text { de mulas }\end{array}$ & $\begin{array}{c}\text { Vendidas } \\
\text { a crédito }\end{array}$ & $\%$ \\
\hline $1750 / 1755$ & 150.011 ps 6 r. & 9 ps. & 144.000 & 16.668 & 11,6 \\
$1770 / 1775$ & 461.228 ps 7 r. & 7 ps. & 198.000 & 65.890 & 33,3 \\
$1780 / 1785$ & 256.053 ps 4 r. & 6 ps 4 r. & 118.256 & 39.393 & 33,3 \\
$1790 / 1795$ & 120.318 ps & 10 ps & 94.258 & 12.031 & 12.7 \\
$1800 / 1805$ & 1.130 .443 ps & 14 ps & 209.071 & 80.746 & 38.6
\end{tabular}

Es decir, que en los momentos de expansión de la demanda el crédito se incrementa. Sin embargo, a diferencia de lo sucedido en los años de la década de 1770, en esta segunda fase de expansión del comercio mular iniciada en 1796, la demanda crece por encima de las posibilidades de producción de la región del litoral y Córdoba, de manera tal que el precio aumenta, favoreciendo ampliamente a los ganaderos. Como consecuencia de la excesiva demanda, las mulas que se remiten al Perú no reúnen las condiciones necesarias para el viaje. Por eso la mortandad producida en 1802 entre las tropas de mulas remitidas a Jauja y a Lima es atribuida a la circunstancia de haber salido de las tabladas de Salta flacas y de poca edad, sin la fortaleza necesaria para afrontar el largo y penoso viaje de más de 400 leguas. $^{8}$

7 Archivo y Biblioteca Históricos de Salta-Archivo Notarial (en adelante ABHS-AN), Protocolos. Salta, 1750-1810, y Sánchez Albornoz, Nicolás: “La saca de mulas ...”, págs. 275 y 293. Efectuado el mismo cálculo con datos referidos al año 1765, se observa que el porcentaje de mulas internadas a crédito es del 9,5\%. Este resultado permite comprobar que el incremento del crédito en el rubro mular se verifica a partir de 1770 . Aumentando el comercio, aumenta el crédito y se acelera la circulación.

8 Telégrafo Mercantil, Rural, Político, Económico e Historiográfico del Río de la Plata (1801-1802). Reimpresión facsimilar. Junta de Historia y Numismática Americana. Buenos Aires, 1915, págs. 304 a 308. 
El incremento del precio de las mulas en esta primera década del siglo XIX, unido al del porcentaje de mulas vendidas a crédito, endeudan fuertemente a los comerciantes peruanos y altoperuanos con los estancieros y criadores de mulas de Córdoba, Santa Fe, Buenos Aires y Santiago del Estero, en tanto adquieren importancia los intermediarios salteños que representan los intereses de unos y de otros oficiando de fiadores y habilitadores. El 80\% de las mulas internadas entre 1800 y 1809 no abonan la sisa, cuya deuda es afianzada por comerciantes vecinos que responden a la Real Hacienda con sus bienes.

\section{Características del crédito mercantil}

\section{Garantías exigidas}

A diferencia del dinero otorgado por la Iglesia (órdenes religiosas, cofradías, hermandades) o por particulares (bienes de menores o viudas), el crédito mercantil se caracterizaba por la inexistencia casi generalizada de hipotecas de bienes raíces que aseguraban la operación, salvo en aquellos casos en que el deudor resultara insuficientemente fiable o sólido. Analizando las cartas de créditos protocolarizadas ante el escribano del Cabildo de Salta es posible observar, en términos generales, que un altísimo porcentaje de las mercancías entregadas a crédito no requerían para ello una garantía en especial. Por supuesto, la fórmula existente en toda carta de crédito hacía referencia, junto con la obligación de pago en los plazos y lugares fijados, a la posibilidad de la ejecución de los bienes del deudor en caso de no cancelarse dichas obligaciones.

Las garantías ofrecidas, cuando éstas fueron exigidas, eran de diferentes tipos. Se utilizaban para tal fin propiedades urbanas o rurales, esclavos, cartas comerciales o los efectos o mercancías adquiridos en la operación. También se recurría a un fiador, generalmente un vecino comerciante de suficiente "abono", quién se hacía responsable en caso de incumplimiento del deudor. Analizadas las cartas de crédito con detenimiento, podemos comprobar que cuando las mismas corresponden a la adquisición de mulas y a la habilitación de tropas, dichas operaciones se garantizaban casi exclusivamente con las mismas mulas o por medio de un fiador. Solamente en los años 1790-1795 encontramos gravadas algunas propiedades urbanas. En realidad la hipoteca de propiedades urbanas o rurales era más frecuen- 


\section{Gráfico III}

\section{Crédito por períodos}

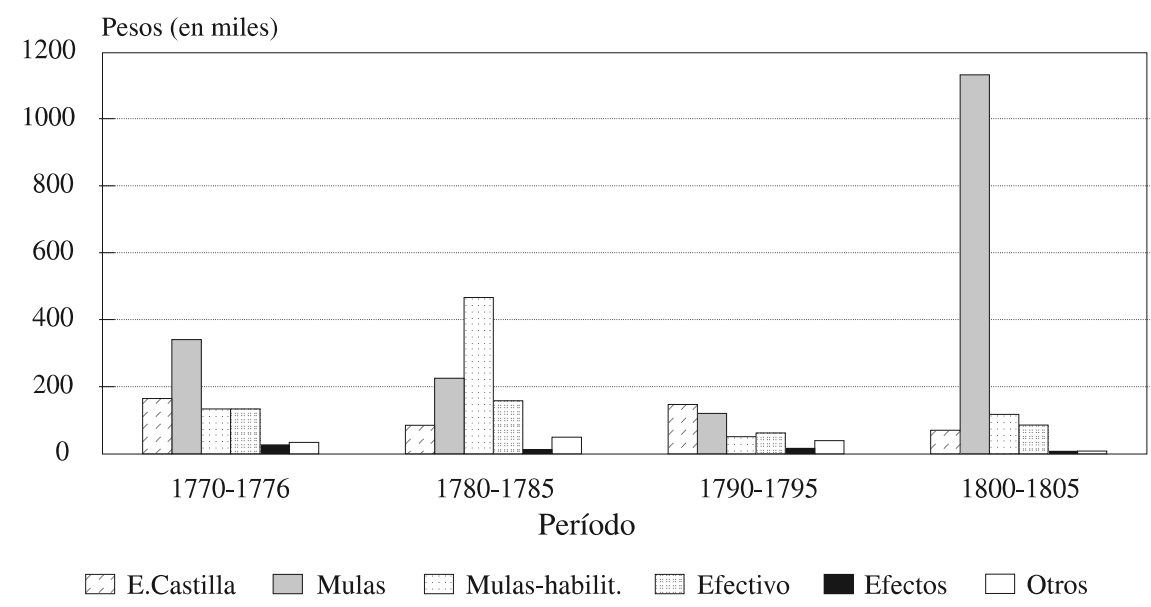

Fuente: ABHS, Protocolos Notariales, 1770-1805

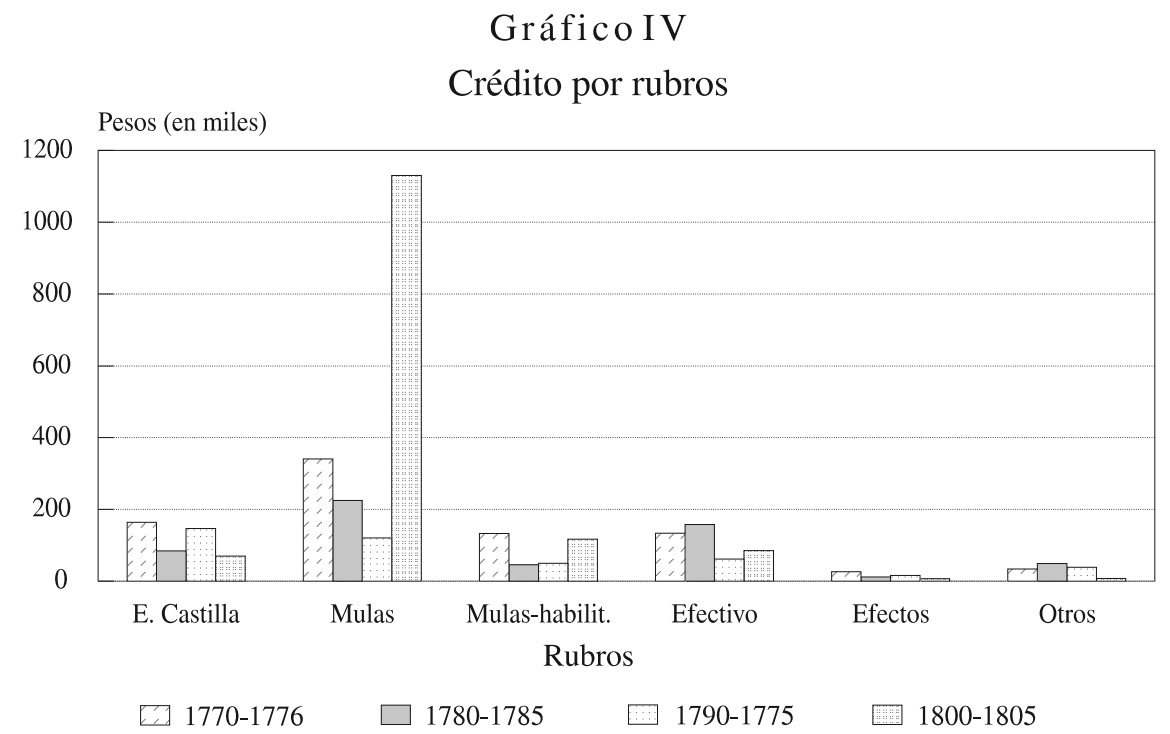

Fuente: ABHS, Protocolos Notariales, 1770-1805 
te cuando el motivo de la deuda era dinero. En algunos casos, si se manifestaba que el préstamo de dinero efectivo se hacía con la finalidad de adquirir otras mercancías, se ponían como garantía esas mismas mercancías. También encontramos fiadores en este tipo de operaciones.

Sin embargo, los períodos estudiados no son uniformes al respecto. Así, mientras entre 1770-1775 y 1780-1785, el 93.3\% del crédito mercantil no registró garantías o hipotecas de ninguna naturaleza, en 1790-1795 dicho porcentaje disminuyó al 77.5\%. ${ }^{9}$ Si relacionamos estos datos con los montos totales del crédito mercantil que en los años 1790-1795 fue el de menor volumen, y recordamos que durante esos años tuvo lugar una importante retracción del comercio mular, comprobaremos que el comportamiento de los acreedores reflejó las inseguridades económicas del momento. El estudio del crédito es en este sentido un indicador importante de las crisis económicas.

Es interesante comprobar en qué rubros las exigencias de garantías hipotecarias o de fiadores eran más frecuentes, según las décadas.

PORCENTAJE DEL CRÉDITO GARANTIZADO POR RUBROS Y PERÍODOS

\begin{tabular}{|c|c|c|c|c|}
\hline Rubros & $\begin{array}{c}1770-1775 \\
\%\end{array}$ & $\begin{array}{c}1780-1785 \\
\%\end{array}$ & $\begin{array}{c}1790-1795 \\
\%\end{array}$ & $\begin{array}{c}1800-1805 \\
\%\end{array}$ \\
\hline Ef. Castilla & 1.3 & 8.4 & 4.6 & 2.0 \\
\hline Esclavos & - & - & - & - \\
\hline Mulas & 2.4 & 3.1 & 3.3 & 8.0 \\
\hline Mulas-Habilitación & 30.2 & - & 92.5 & - \\
\hline Ganado & - & $17.3^{*}$ & - & - \\
\hline Ef. tierra & 69.2 & - & - & - \\
\hline Dinero & 6.9 & 12.5 & 39.7 & 36.4 \\
\hline Habilitación & 3.7 & 9.4 & - & - \\
\hline Efectos & 13.8 & 10.0 & 8.2 & 13.6 \\
\hline Ajustes cuentas & - & 5.0 & 56.2 & - \\
\hline Otros & - & - & - & $100.0^{*}$ \\
\hline
\end{tabular}


Al considerar los porcentajes sobre el monto total del crédito en cada uno de los rubros a los que estaba destinado, que corresponden a operaciones con garantías explicitadas, observamos que las mulas no requieren de mayores garantías ya que en general eran adquiridas por comerciantes peruanos y altoperuanos a través de apoderados, casi siempre vecinos de Salta. Con las habilitaciones y los efectos de Castilla, sucedía algo similar. Cuando el crédito incluía, junto con las mulas, la habilitación de las tropas (salarios de los peones, cabalgaduras, etc.) resulta significativo que en los años 1790-1796, en los cuales se manifiesta la mayor retracción del comercio mular y cuando tan sólo el $12.7 \%$ de las mulas eran comercializadas a crédito, la casi totalidad de las operaciones hayan requerido garantías. Es asimismo en estos años cuando los préstamos de dinero y los ajustes de cuentas se realizaron con mayores recaudos. Estas evidencias ratifican lo afirmado anteriormente en relación con la crisis económica observada en esos años.

Generalmente las propiedades rurales o urbanas fueron utilizadas con mayor frecuencia para garantizar las operaciones cuando las deudas se debían a préstamos de dinero. Así, de los 19.755 ps., 2 rs. prestados en dinero efectivo entre 1780-1785, hipotecando algún bien, 17.254 ps., 2 rs. consignaron propiedades como garantía. De la misma manera, entre 1790$1795,23.753$ ps., 6 rs. de los 24.556 ps., 2 rs. fueron otorgados gravando propiedades. Sólo en contadas ocasiones se hipotecaron esclavos o los efectos adquiridos con el dinero solicitado o se recurrió a un fiador. ${ }^{10}$

Los créditos por venta de mulas, al igual que las habilitaciones de tropas, por el contrario, no sólo fueron garantizadas en menor proporción sino que cuando lo hicieron, establecieron una hipoteca especial sobre las mismas mulas, o se valieron de un fiador y en muy pocos casos se garantizó la operación a través de bienes inmuebles. Finalmente, los créditos por efectos de Castilla, escasamente garantizados, recurrieron muy esporádicamente al gravamen de propiedades y más frecuentemente respaldaron la operación con la hipoteca de esclavos o de las mercancías adquiridas. Es interesante comprobar que solamente en dos oportunidades fueron utilizadas acreencias como garantía y sólo en un caso por un préstamo de 10.128 pesos en efectivo, realizado en $1800 .^{11}$

10 Ibídem. Montos de dinero efectivo otorgado a préstamos, según los períodos estudiados: $1770-1775,30.428$ ps; $1780-1785,79.182$ ps; $1790-1795,30.372$ ps, y $1800-1805,62.320$ ps.

11 Ibídem, Protocolo 193, Carpeta 19, fol. 125. Salta, 1800. 


\section{Cumplimiento de las obligaciones}

En el cumplimiento de las obligaciones contraídas no parece haber incidido demasiado la existencia de garantías explícitas o su ausencia, pues siempre es similar. En muchos casos, abonada la deuda se inscribía en los márgenes de la obligación la fecha de cancelación, así sobre un total de 595 registros solamente encontramos cancelados 335 y de los 260 restantes carecemos de datos. Por supuesto que esto no significa de ningún modo incumplimiento. Muchas veces las cancelaciones se realizaban en otros lugares y no se procedía luego a inscribirlo en los protocolos, o esas cartas de deudas circulaban entre los comerciantes hasta su cancelación, sin que su caducidad constara en el instrumento público archivado en el Cabildo. De todas maneras, cuando los deudores eran vecinos comerciantes o estancieros de la ciudad de Salta, existiese o no en las cartas de crédito la hipoteca de sus propiedades, la falta de pago de sus créditos concluyó con el remate de sus bienes para proceder a saldar sus deudas. Las bancarrotas y quiebras de Francisco Gavino Arias Rengel, Manuel Salvador Fernández, Valentín de la Camara y Lorenzo de Gordaliza, todos ellos vecinos de Salta, fueron notorias. Los expedientes judiciales muestran que los pleitos por cobros de pesos eran bastante frecuentes.

En general el crédito mercantil no requirió de hipotecas para ser otorgado y el grado de cumplimiento de estas obligaciones parece haber sido satisfactorio. Los montos de los créditos acerca de los cuales existe constancia de su cancelación, varía según los años, observándose un mayor cumplimiento a partir de 1780. Coincide, no obstante, entre 1790-1795, un mayor porcentaje de créditos con garantías $(22.5 \%)$ junto con la mayor proporción de créditos con datos de cancelación (67.7\%).

\section{Plazos e intereses}

Si bien las cartas de crédito no siempre establecían una garantía o hacían constar las cancelaciones, sí explicitaban los plazos con los cuales eran otorgados los créditos. Intímamente ligado con el plazo se hallaba el interés ya que, con excepción del préstamo de dinero efectivo, en la venta de mercancías (sean éstas mulas, efectos de Castilla o de la tierra) se indicaba taxativamente que vencido el plazo de pago comenzarían a correr los intereses. Sin embargo, en tanto los plazos fijados para la cancelación de la 
deuda se encuentran en 493 de las 595 obligaciones de pago registradas, solamente 116 indican el porcentaje de interés anual pactado, ya que la mayoría señala que vencido el plazo "correrán los intereses según práctica y estilo del comercio". Era usual otorgar 12 meses de plazo para proceder a su cancelación o para comenzar a aplicar los intereses. Hemos observado que sobre 493 cartas de crédito que registran plazos, el 62.7\% de los mismos se hallan comprendidos entre los 7 y 12 meses, correspondiéndole a este último lapso algo más del $50 \%$ de los casos. ${ }^{12}$

Es interesante señalar que estos eran los plazos más frecuentes en el comercio mular, incluyendo en él las habilitaciones para pagar salarios de los peones y adelantos de dinero con el mismo fin. Los créditos a plazos inferiores correspondían generalmente, en proporciones similares, al comercio mular, al préstamo de efectivo o al adelanto de efectos de Castilla. Finalmente, los plazos superiores a 24 meses corresponden a efectos de Castilla y dinero. Debemos señalar que en 1780, 1784 y 1795, en momentos críticos para el comercio regional (en la década del 80 por las rebeliones altoperuanas y luego por la saturación de los almacenes de Buenos Aires de mercancías de ultramar, incluidos los aguardientes y vinos catalanes, tras reanudarse el comercio con España y en 1795 por la contracción del comercio mular), encontramos dos obligaciones con 4 años de plazo y una con 5 , correspondiendo a ajustes de cuentas y préstamo de dinero. ${ }^{13}$

Cuando en las cartas de crédito se hacía referencia a los intereses "usuales" para el comercio, el mismo era - al parecer- superior al 5\% autorizado y tolerado por la costumbre. A pesar de que la mayoría de las cartas de crédito no estipulan los intereses de éste, entre aquellas que sí lo hicieron encontramos que el 55\% se pacta al 5\% anual, correspondiendo en la mayoría de los casos a préstamos de dinero efectivo, mientras que el 43\% de los restantes corresponde a un interés del 6\% y abarca no sólo dinero en efectivo sino también efectos de Castilla, mulas, habilitaciones y ajustes de cuentas. Era al parecer el interés más "usual" en el comercio. Esta apreciación parece confirmarse a través de una carta de crédito otorgada por Nicolás Severo de Isasmendi, vecino hacendado de Salta, que se com-

12 Ibídem, Protocolos. Salta, 1750-1810. Plazos otorgados y cantidad de obligaciones: 1 a 6 meses, 131; 7 a 12 meses, 309; 13 a 24 meses, 41; 25 a 36 meses, 9; 48 meses, 2; 60 meses, 1, y sin datos, 103. Esto da un total de 596 obligaciones.

13 Ibídem, Protocolo 150, Carpeta 15, fol. 33. Salta, 1780; Protocolo 155, Carpeta 16, fol. 82. Salta, 1784; Protocolo 176, Carpeta 18, fol. 15v. Salta, 1795. 
promete a pagar en 36 meses una deuda contraída con un vecino de Buenos Aires por efectos de Castilla y dinero que le ha adelantado en 1790, abonando en caso de atrasarse el "medio por ciento al mes, según práctica y estilo del comercio". ${ }^{14} \mathrm{Al}$ parecer, solamente con carácter excepcional se cobraron intereses más elevados en algunas circunstancias y así encontramos dos préstamos de dinero efectivo efectuados por el juez eclesiástico de Salta a un vecino de La Rioja y a un sacerdote de la misma ciudad, cuyo interés era del $8 \%$ anual. $^{15}$

\section{Acreedores y deudores. La dinámica comercial}

Una de las mayores dificultades existentes cuando intentamos estudiar el crédito es identificar a quiénes otorgan el crédito y a quiénes lo toman. Particularmente difícil es mensurar en que medida los vecinos que aparecen como acreedores actúan como apoderados de vecinos o residentes de otras ciudades (comerciantes, hacendados, mineros o corregidores). Se han registrado como acreedores no vecinos a aquellos que especificaron su condición de residente o que, al concretarse o cancelarse la obligación, los apoderados hicieron mención del acreedor, en algunos casos consignando la ciudad de la cual era vecino. Es de suponer que muchas veces, aún cuando el acreedor fuera un vecino, las mulas o efectos de Castilla que entregó a crédito le pudieron haber sido confiadas por comerciantes ajenos a la ciudad. Finalmente, no ha sido posible identificar a algunos acreedores y deudores. De todas maneras, y a pesar de estas reservas en cuanto a la procedencia efectiva del capital mercantil, resulta de interés agrupar a los acreedores y deudores de acuerdo a su vecindad, por cuanto permite apreciar el papel de la ciudad de Salta en los procesos mercantiles del espacio andino.

La dinámica del comercio regional es particularmente evidente. En los años correspondientes a fases de expansión del comercio mular el porcentaje del crédito otorgado y tomado por comerciantes de otros lugares se incrementa notablemente. Esto demuestra que en Salta se concretaban anualmente los negocios de comerciantes provenientes de diferentes y en algunos casos distantes regiones, reflejando las alternativas económicas del espacio peruano.

14 Ibídem, Protocolo 164, Carpeta 17, fol. 99. Salta, 1790.

15 Ibídem, Protocolo 138, Carpeta 13, fol. 200. Salta, 1773. 
ACREEDORES Y DEUDORES. PARTICIPACIÓN PORCENTUAL DEL MONTO TOTAL DEL CRÉDITO

\begin{tabular}{|c|c|c|c|c|c|c|}
\hline \multirow[t]{2}{*}{ Períodos } & \multicolumn{3}{|c|}{ Acreedores } & \multicolumn{3}{|c|}{ Deudores } \\
\hline & $\begin{array}{c}\text { Vecinos } \\
\%\end{array}$ & $\begin{array}{c}\text { No vecinos } \\
\%\end{array}$ & $\begin{array}{c}\text { S/datos } \\
\%\end{array}$ & $\begin{array}{c}\text { Vecinos } \\
\%\end{array}$ & $\begin{array}{c}\text { No vecinos } \\
\%\end{array}$ & $\begin{array}{c}\text { S/datos } \\
\%\end{array}$ \\
\hline $1770-1775$ & 27.7 & 59.3 & 13.0 & 32.8 & 59.5 & 7.7 \\
\hline $1780-1785$ & 44.9 & 50.9 & 4.2 & 52.5 & 43.2 & 4.3 \\
\hline $1790-1795$ & 47.5 & 48.2 & 4.3 & 62.9 & 28.1 & 9.0 \\
\hline $1800-1805$ & 28.2 & 70.0 & 1.8 & 15.1 & 76.2 & 8.7 \\
\hline
\end{tabular}

Fuente: ABHS-AN, Protocolos. Salta, 1750-1810.

Por las mismas razones, entre 1780-1785 y 1790-1795, al disminuir la demanda y comercialización de mulas, los vecinos de la ciudad registran un endeudamiento mayor, al ser menor el porcentaje que corresponde al crédito mular. No es tampoco casual, que en la década de 1790-1795, los comerciantes no vecinos solamente hayan participado en un $28.1 \%$ del total del crédito en calidad de deudores, en tanto los vecinos registran un mayor endeudamiento.

En cuanto a su condición de acreedores o deudores, los comerciantes vecinos de Salta, tuvieron diferente participación de acuerdo con el motivo del préstamo o endeudamiento:

Períodos acreedores deudores

Dinero Mulas E.Cast. Hab. Dinero Mulas E.Cast. Hab.

\begin{tabular}{rrrrrrrrr}
\hline $1770-1775$ & 22.8 & 29.1 & 20.7 & 43.4 & 65.2 & 28.2 & 22.5 & 16.8 \\
$1780-1785$ & 65.9 & 28.5 & 65.9 & 69.9 & 21.1 & 76.8 & 21.1 & 74.2 \\
$1790-1795$ & 49.1 & 41.4 & 42.1 & 100.0 & 59.1 & 82.0 & 57.2 & 50.4 \\
$1800-1805$ & 73.2 & 13.7 & 81.3 & 100.0 & 56.8 & 9.2 & 69.7 & 3.1
\end{tabular}

Fuente: ABHS-AN, Protocolos. Salta, 1750-1810.

Al discriminar los rubros más relevantes del crédito, comprobamos que en el mular los comerciantes vecinos de Salta disminuyeron porcentualmente su participación como acreedores en los años 1800-1805, en tanto en los momentos de mayor contracción de ese comercio, es decir 1780 a 1795, fueron los principales deudores. 
En trabajos anteriores habíamos sostenido que los medianos y grandes estancieros de Salta en las últimas décadas del siglo XVIII habían sido desplazados del comercio mular, ${ }^{16}$ y que particularmente durante la primera década del siglo XIX este comercio fue monopolizado por apoderados y comerciantes residentes. También sostuvimos que las rebeliones altoperuanas de 1780-1781, provocaron la quiebra de los comerciantes - tanto residentes como vecinos de Salta - que internaban mulas por su cuenta, costo y riesgo. Entre 1800-1809 la mayor parte de las mulas se internaban por cuenta y riesgo de los mineros y comerciantes peruanos y altoperuanos. ${ }^{17}$ Es por todo ésto que los vecinos de Salta disminuyeron en forma paulatina la cantidad de mulas tomadas a crédito. En este sentido, el proceso observado en el crédito mular reafirma las conclusiones a las que arribáramos en los trabajos anteriormente citados al marcar la misma tendencia.

\section{CRÉDITO EN MULAS TOMADO POR COMERCIANTES VECINOS}

\begin{tabular}{lccc} 
Períodos & Monto & Precio estimado & Mulas estimadas \\
\hline $1770-1775$ & 95.939 ps. $7 \mathrm{r}$ & 7 ps. & 13.705 \\
$1780-1885$ & 64.097 ps. $7 \mathrm{r}$ & 6 ps. $4 \mathrm{r}$ & 9.861 \\
$1790-1795$ & 49.766 ps. $1 \mathrm{r}$ & $10 \mathrm{ps}$. & 4.976 \\
$1800-1805$ & 154.439 ps. 6r & 14 ps. & 11.031 \\
\hline
\end{tabular}

Fuente: ABHS-AN, Protocolos. Salta, 1750-1810.

Recuperado el comercio mular a principios del siglo XIX, los comerciantes de Salta no alcanzarán de todas maneras los niveles de participación de la década de 1770. Los no vecinos, tanto acreedores como deudores, dominarán la escena mercantil en este rubro.

Sin embargo, son los créditos por habilitación de tropas los mejores indicadores de las incidencias del comercio mular en la economía regional, y particularmente en la consolidación del grupo mercantil en la ciudad de Salta.

16 Mata de López, Sara: "Economía agraria y sociedad en los valles de Lerma y Calchaquí. Fines del Siglo XVIII", Anuario del IEHS, n. ${ }^{\circ}$ 6. Tandil, Argentina, 1991, pág. 70.

17 Mata de López, Sara: "Los comerciantes de Salta a fines del Siglo XVIII", Anuario IIHR, n. ${ }^{\circ}$ 16, Rosario, 1994, pág. 199. 


\section{Gráfico V}

Acreedores. 1770-1775

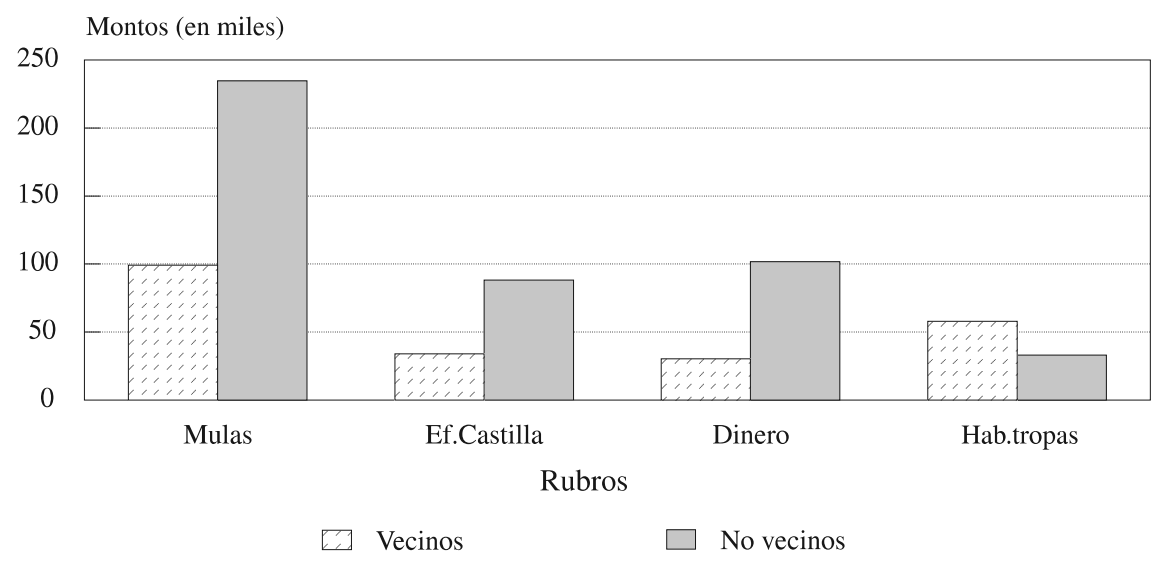

Fuente: ABHS, Protocolos Notariales, 1770-1775

\section{Gráfico VI}

Acreedores. 1780-1785

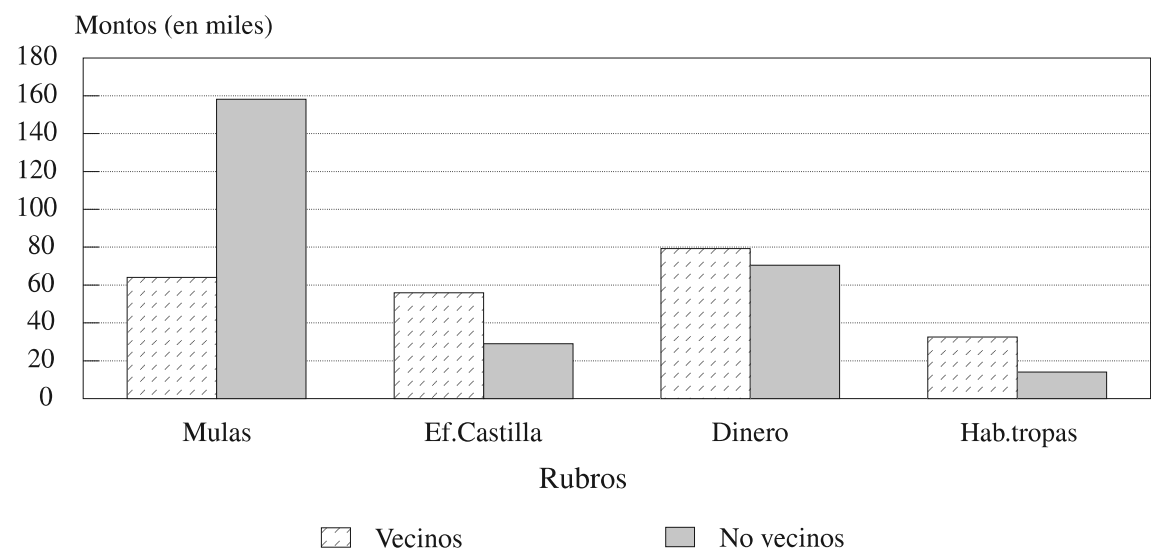

Fuente: ABHS, Protocolos Notariales, 1780-1785 


\section{Gráfico VII}

Acreedores. 1790-1795

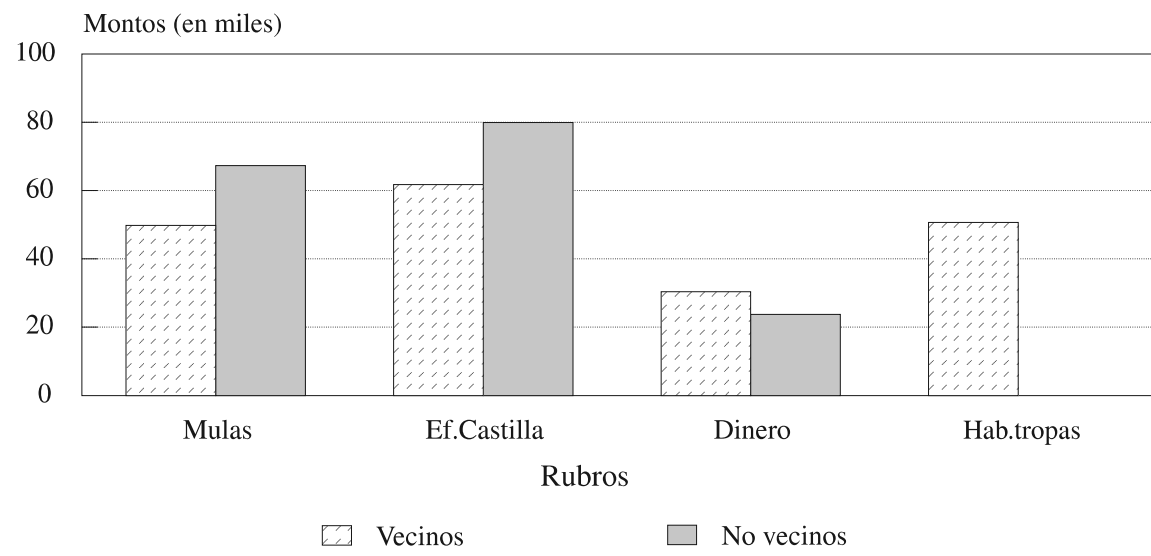

Fuente: ABHS, Protocolos Notariales, 1790-1795

\section{Gráfico VIII}

Acreedores. 1800-1805

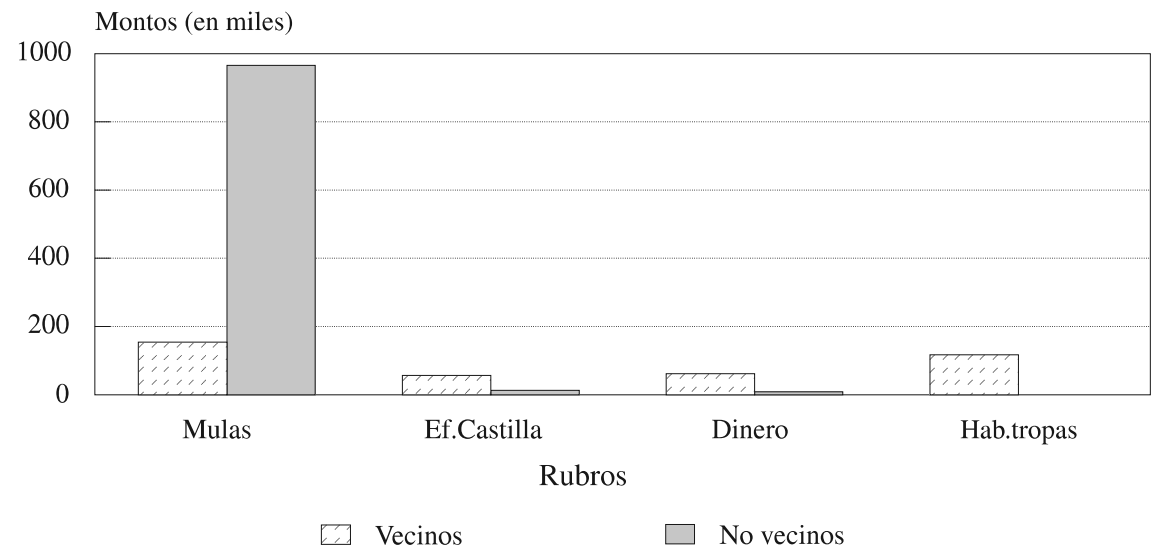

Fuente: ABHS, Protocolos Notariales, 1800-1805

164 
Efectivamente, los comerciantes salteños monopolizarán en las dos últimas décadas del período colonial la habilitación de tropas de mulas con efectos de Castilla, de la tierra e incluso dinero para los salarios de los peones y avíos necesarios para el viaje. A pesar de que parte de las mercancías existentes en sus tiendas les habían sido adelantadas por los comerciantes mayoristas de Buenos Aires, es importante destacar este proceso de consolidación e inserción que alcanzaron en la actividad mercantil de Salta. Igualmente sugestivo resulta que entre 1800 y 1805 solamente un $3.1 \%$ del crédito por habilitaciones haya sido tomado por comerciantes vecinos, ya que quienes internan las mulas por su cuenta, costo y riesgo son, sin duda, los comerciantes peruanos y altoperuanos. La participación de los vecinos salteños en la internación de las mulas es más significativa en los períodos de depresión del comercio mular.

El crédito en efectos de Castilla permite observar en la primera década del siglo XIX el afianzamiento de los comerciantes que operan primordialmente en ese rubro. Especialmente cuando comparamos los montos correspondientes a 1770-1775, donde la mayor parte de la comercialización de los efectos de Castilla era realizada por comerciantes peninsulares no avecindados en la ciudad y otros muchos que se instalaban temporalmente en Salta para efectuar sus negocios en representación de los principales almacenes de Buenos Aires. Algunos de estos comerciantes residentes en 1770 ya son vecinos de Salta en la década siguiente. ${ }^{18}$

Por último, los préstamos en efectivo son los más complicados de analizar. El criterio adoptado ha sido considerar el dinero (que en algunos casos era otorgado por viudas o por sacerdotes) como parte del crédito mercantil cuando quienes lo tomaban eran comerciantes, ya que aún cuando no explicitaran el destino que otorgarían al mismo, es de suponer que se volcaría en la circulación mercantil. De la misma manera, también consideramos dentro del crédito mercantil a aquel otorgado por los comerciantes a vecinos y estancieros de Salta con el fin de invertirlo en sus propiedades. ${ }^{19}$

El incremento en el porcentaje del crédito en efectivo que registran como acreedores los comerciantes vecinos de Salta, demuestra también el afianzamiento de éstos en la ciudad. De todas maneras, observando no los

18 Mata de López, Sara: "Economía agraria y sociedad...”, pág. 72.

19 El interés demostrado por los comerciantes en la adquisición de propiedades urbanas, respondió no sólo a una inversión destinada a incrementar sus rentas a través de los alquileres que podían obtener de ellas, sino también a la posibilidad de conseguir dinero a bajo interés y riesgo, a través de créditos, eclesiásticos cuando fuere necesario. 
porcentajes sino los montos totales de los préstamos otorgados por vecinos de la ciudad de Salta, comprobaremos que en 1770-1775 el mismo fue similar a los años $1790-1795,{ }^{20}$ lo cual ratifica nuevamente lo ya afirmado acerca de la crisis económica observable durante esos años y la retracción del comercio en general y del mular en particular.

Los comerciantes y mineros del Alto Perú e incluso de Lima ofrecieron a los vecinos de Salta la posibilidad de obtener préstamos en dinero efectivo. Hemos recogido numerosos testimonios referidos a estos préstamos que los vecinos de Salta conseguían valiéndose de apoderados o representantes. ${ }^{21}$ No siempre se consignaba el destino del dinero solicitado, pero hemos registrado préstamos para adquirir mercancías, habilitar tropas de mulas, poblar una estancia, concluir la construcción de una vivienda e incluso abonar los salarios en un ingenio de mineral. Muchas veces se acordaba la devolución del dinero en "efectos de la tierra" como azúcar de Arequipa, lienzo de Oruro y el Cuzco, ají, algodón y lienzo del valle de Catamarca, o jabón y sebo del valle de Lerma. ${ }^{22}$ En estos casos, los créditos monetarios semejan compras por adelantado y ejemplifican el dominio del capital mercantil sobre la producción, a la que condiciona. Se hace necesario distinguir entonces las distintas formas que asume el capital comercial, ya que tanto el crédito monetario que es reintegrado a través de mercancías como el que se otorga para la adquisición de éstas entran en la esfera del capital comercial, junto con las ventas a crédito de las mercaderías, en tanto que los préstamos que representan una forma de invertir dinero acumulado con el interés de una renta, son capital usurario.

Finalmente, a través del crédito otorgado por comerciantes vecinos o residentes de otras ciudades del litoral y del espacio andino es posible valorar las estrechas vinculaciones mercantiles interregionales y el peso de cada región en la actividad comercial de la ciudad. Dado que el crédito en mulas era por su monto el más importante, no debe extrañarnos el descubrir que los principales acreedores en dicho rubro proceden mayoritariamente de Córdoba, y en menor medida de Santa Fe, Buenos Aires y Santiago del Estero. Los deudores provendrán en primer lugar de Lima pero también de otros lugares del espacio andino.

20 ABHS-AN, Protocolos. Salta, 1750-1810. Los montos de dinero prestados por vecinos de Salta durante los períodos estudiados fueron los siguientes: $1770-1775,30.428$ ps; $1780-1785$, 79.182 ps; $1790-1795,30.372$ ps, y 1800-1805, 62.320 ps.

21 Ibídem, Protocolo 144, Carpeta 14, fol. 86v.; Protocolo 127, Carpeta 11, fol. 128.

22 Ibídem, Protocolo 157, Carpeta 16, fol. 31v.; Protocolo 159, Carpeta 16, fol.1; Protocolo 160, Carpeta 16, fols. 30-36; Protocolo 142, Carpeta 13, f. 76v. 


\section{Gráfico IX}

\section{Acreencias de Córdoba}

Mulas. 1770-1805

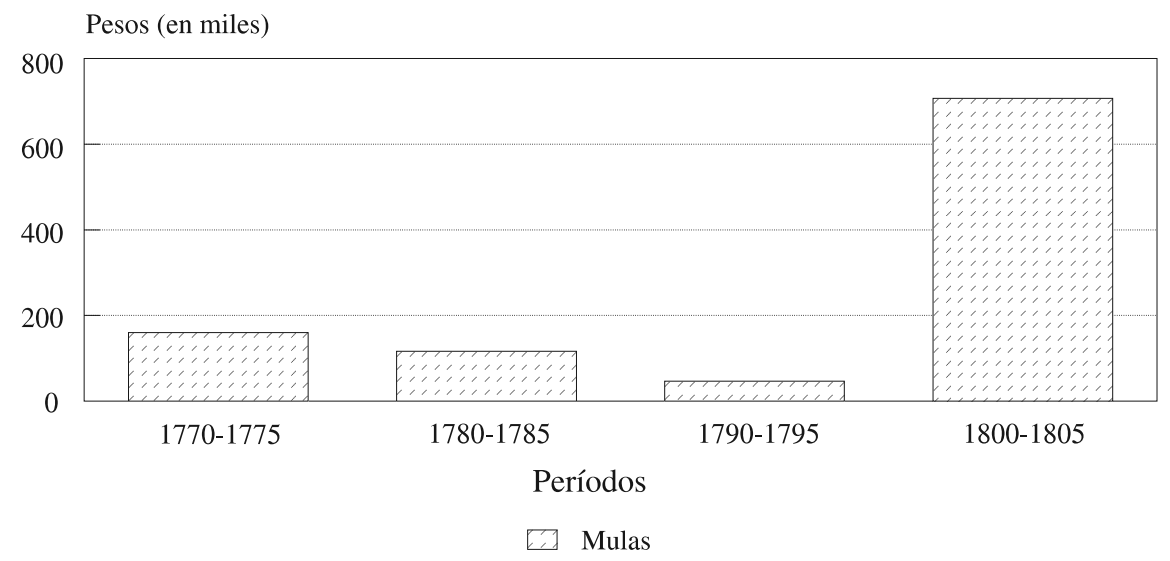

Fuente: ABHS, Protocolos Notariales, 1770-1805

\section{Gráfico X}

Acreencias de Córdoba

Por rubros 1770-1805

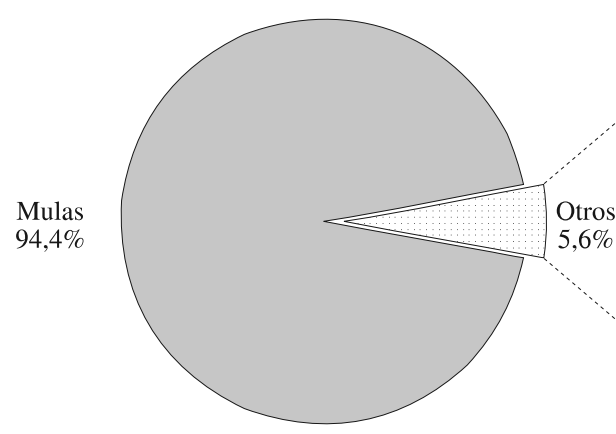

Total

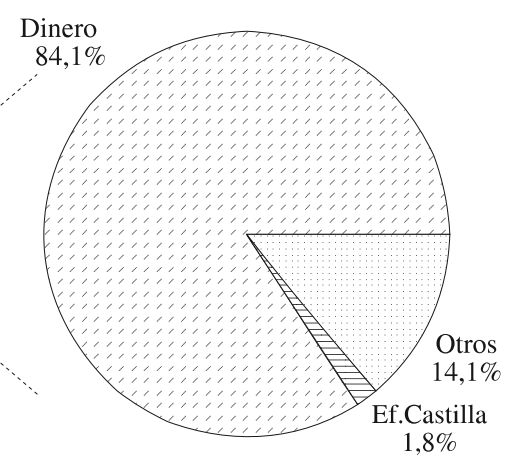

Otros

Fuente: ABHS, Protocolos Notariales, 1770-1805. 
Al considerar los comerciantes no vecinos de Salta, podremos comprobar que las mercancías movidas en la ciudad proceden de unas pocas regiones. Por el contrario, concurren a Salta con el fin de adquirir esas mercancías comerciantes de numerosos lugares. Esto confirma el papel de Salta como centro del espacio andino y el predominio de algunas regiones en determinados rubros mercantiles. Así, las acreencias de Córdoba registradas en Salta corresponden a la venta de mulas en un $94.5 \%$, mientras que el crédito restante se debe a préstamo de dinero. De la misma manera el motivo de las acreencias de Santa Fe, Santiago del Estero y Tucumán son las mulas. Por el contrario, el crédito procedente de Buenos Aires está compuesto en un $46.9 \%$ de efectos de Castilla, un $19.4 \%$ en mulas, un $15 \%$ en dinero y el $18.7 \%$ restante se debe a ajustes de cuentas y a efectos varios..$^{23}$

Los créditos otorgados por los comerciantes y mineros de Lima, Chucuito y La Paz fueron casi exclusivamente por préstamos de dinero efectivo concedidos tanto a vecinos de Salta como a vecinos de Santiago del Estero y Córdoba. La devolución del préstamo en algunos casos consistía en mercancías tales como jabón, ganado, lienzo o mulas. Por su parte, los comerciantes del Cuzco vendieron en Salta a crédito ropa de la tierra.

Desagregados por años los créditos que los comerciantes de Buenos Aires otorgan en Salta comprobamos que no se registra ninguna operación durante los años 1800-1805. ${ }^{24}$ Si relacionamos estos datos con los que obtuvimos acerca del alto porcentaje de participación que en esos mismos años tuvieron los vecinos de Salta en los créditos en efectos de Castilla y en la habilitación de tropas, podemos considerar que estos comerciantes que poseen tiendas importantes surtidas de esos efectos y que habilitan las tropas de mulas que parten al Perú ya no son meros apoderados y representantes de las casas comerciales de Buenos Aires, sino que toman créditos importantes en dichas casas comerciales y los otorgan por su cuenta, costo y riesgo a otros comerciantes de menor giro, tanto locales como vecinos de otros lugares. ${ }^{25}$

23 Ibídem, Protocolos. Salta, 1750-1810.Los créditos otorgados por comerciantes de Buenos Aires en los períodos estudiados fueron: Efectos de Castilla, 124.582 ps. (46.9\%); mulas, 51.582 ps. (19.4\%); efectivo, 39.904 ps. (15.0\%); Ajustes de cuentas, 34.173 ps. (12.9\%); efectos, 12.659 ps. (4.8\%), y otros, 2.858 ps. (1.0\%). El total era 265.758 ps. (100.0\%).

24 Ibídem, Protocolos. Salta, 1750-1810. Los créditos otorgados por comerciantes de Buenos Aires desagregados por quinquenios supusieron: 1770-1775, 111.350 ps; 1780-1785, 44.879 ps; 1790 $1795,109.529$ ps, y de 1800-1805, se desconoce.

25 Ibídem, Protocolo 156, Carpeta 16, fol. 70. 


\section{CANTIDAD DE OPERACIONES Y MONTOS DE LOS CRÉDITOS DE COMERCIANTES ${ }^{(1)}$ DE OTROS LUGARES ${ }^{(2)}$}

Lugar

acreedores

deudores

\begin{tabular}{|c|c|c|c|c|}
\hline & Operaciones & Monto & Operaciones & Monto \\
\hline Arequipa & - & - & 4 & 54.442 ps. $1 \mathrm{r}$ \\
\hline Atacama & - & - & 2 & 828 ps. $7 \mathrm{r}$ \\
\hline Belén & - & - & 3 & 5.251 ps. $7 \mathrm{r}$ \\
\hline Buenos Aires & 48 & 265.758 ps. $7 \mathrm{r}$ & 5 & 17.834 ps. $3 r$ \\
\hline Catamarca & - & - & 2 & 2.925 ps. \\
\hline Cochabamba & - & - & $1 \overline{5}$ & 99.270 ps. \\
\hline \multicolumn{5}{|l|}{ 1r } \\
\hline Cordoba & 110 & 1.111 .460 ps. $7 \mathrm{r}$ & 12 & 100.187 ps. \\
\hline Cuzco & 3 & 10.308 ps & 10 & 102.152 ps. \\
\hline Chancay & - & - & 1 & 22.738 ps. \\
\hline Chichas & - & - & 2 & 8.359 ps. 2 r \\
\hline Chucuito & 4 & 14.700 & - & - \\
\hline Esteco* & - & - & 1 & 522 ps. $5 r$ \\
\hline Escoipe* & - & - & 2 & 3.478 ps. $5 r$ \\
\hline F.Andalgala & - & - & 1 & 82 ps. $3 r$ \\
\hline F.del Rosario & - & - & 1 & 1.500 ps. \\
\hline Huarochuri & - & - & 6 & 205.469 ps. 3r \\
\hline Jauja & - & - & 5 & 102.013 ps. $1 \mathrm{r}$ \\
\hline Jujuy & 12 & 64.485 ps. $4 r$ & 12 & 32.314 ps. \\
\hline La Paz & 1 & 2.000 ps. & 2 & 3.787 ps. $4 \mathrm{r}$ \\
\hline La Rioja & 2 & 3.620 ps. & 5 & 4.024 ps. $6 r$ \\
\hline Las Cañas* & - & - & 1 & 525 ps. $6 r$ \\
\hline Lima & 5 & 28.729 ps. $7 r$ & 30 & 309.775 ps. $6 r$ \\
\hline Pasco & - & - & 1 & 14.207 ps. $4 r$ \\
\hline Potosí & 6 & 17.716 ps. $3 r$ & 12 & 63.784 ps. \\
\hline Puno & - & - & 1 & 34.155 ps. \\
\hline Quebrada Perú* & - & - & 1 & 1.607 ps. $5 r$ \\
\hline R. del Valle* & - & - & 1 & 1.824 ps. $2 \mathrm{r}$ \\
\hline San Carlos* & - & - & 1 & 690 ps. \\
\hline San Juan & 1 & 246 ps. 2 r & 3 & 11.078 ps. $3 r$ \\
\hline Sta. Catalina & - & - & 1 & 650 ps. \\
\hline Santa Fe & 20 & 241.590 ps. & - & - \\
\hline Sta. María & - & - & 2 & 753 ps. 6r \\
\hline Sgo.Estero & 7 & 28.781 ps. & 14 & 64.354 ps. $3 r$ \\
\hline Tarija & - & -1 & 2 & 4.235 ps. $1 \mathrm{r}$ \\
\hline Tomina & - & - & 1 & 4.038 ps. \\
\hline Tucumán & 3 & $8.066 \mathrm{ps}$. & 2 & 2.214 ps. $4 \mathrm{r}$ \\
\hline Yamparaez & - & -1 & 1 & 15.000 ps. \\
\hline
\end{tabular}

Fuente: ABHS-AN. Protocolos. Salta, 1750-1810.

* Localidades pertenecientes a la Jurisdicción de la ciudad de Salta.

(1) Sobre un total de 274 registros de acreedores no vecinos de Salta, registramos 220 con indicación del lugar de vecindad determinada y sobre un total de 281 registros de deudores no vecinos de Salta, registramos 165 con indicación del lugar de origen.

(2) Registros correspondientes a 1770-1775; 1780-1785; 1790-1795 y 1800-1805. 
En efecto, comerciantes de diferentes regiones se endeudan adquiriendo en Salta efectos de Castilla. La mayoría de las cartas de crédito de los comerciantes de Cochabamba corresponden a la compra de efectos de Castilla en una suma total de 72.492 ps., es decir, el $73.0 \%$ del total de las acreencias correspondientes a comerciantes procedentes de dicha región. En menor medida se proveen en Salta a crédito de efectos de Castilla comerciantes de Atacama, Belén (Catamarca), Chichas, Jujuy, La Rioja, San Juan, Santiago del Estero, Tarija y Tucumán. Aún cuando se demuestra así que Salta es un centro de venta de efectos de Castilla, no puede de ninguna manera compararse la importancia de esta actividad con el papel que desempeña en la comercialización de mulas y en la habilitación de las tropas con destino al Perú y al Alto Perú. Por ello los mineros y comerciantes de Lima, Jauja, Arequipa, Potosí, Cuzco y Haurochuri, serán los más fuertemente endeudados por la adquisición de mulas y la habilitación de tropas.

\section{Conclusiones}

El estudio realizado confirma una vez más la enorme gravitación del comercio mular en la economía de Salta en la segunda mitad del siglo XVIII, que convierte a la ciudad en una feria mercantil estacional en la cual se concretaban anualmente los negocios de comerciantes cordobeses, santafecinos y altoperuanos, posibilitando el crecimiento del capital mercantil en la región. Hemos logrado comprobar el proceso de monopolización del comercio mular alcanzado por comerciantes residentes o vecinos de otras ciudades del espacio andino, que culmina en los primeros años del siglo XIX . Los principales beneficios que de este comercio obtendrán los vecinos de Salta derivarán de las invernadas, las habilitaciones, el flete y el papel de afianzadores y apoderados que desempeñaron.

El crédito nos permitió también observar un proceso inverso en relación con otro rubro de particular importancia: los efectos de Castilla. A través de él comprobamos tanto el proceso de radicación de los residentes de origen peninsular, habilitados por los comerciantes porteños, como también el crecimiento económico de los mismos, que en algunos casos intentarán vincularse directamente con las casas comerciales de Cádiz ${ }^{26} \mathrm{O}$

26 Ibídem, Protocolo 138, Carpeta 13, fol. 209. 
tendrán la posibilidad de proveerse en los almacenes de Buenos Aires, pero que al comerciar sus efectos lo harán en su nombre y no en representación de otros. Al finalizar el período colonial los comerciantes de efectos de Castilla, algunos vinculados familiarmente con los que operan en el comercio mular, ${ }^{27}$ han logrado afianzarse en Salta como un poderoso grupo mercantil.

El lugar de residencia o vecindad de los comerciantes que operan en Salta es revelador de la importancia de la ciudad como centro mercantil que vincula al noroeste con el espacio andino, y no sólo por el comercio mular, aún cuando esta vinculación sea factible por la existencia de dicho comercio. Sería importante contar con estudios de otras ciudades, tales como Jujuy, Tucumán y Santiago del Estero para arribar a conclusiones menos provisionales.

27 Mata de López, Sara: "Economía agraria y sociedad...", págs. 72-73, y "Los comerciantes de Salta a fines ...”, págs. 205-206. 